\title{
A LITERATURA INFANTIL NOS PRIMEIROS ANOS ESCOLARES E A PEDAGOGIA DE PROJETOS
}

\section{Cíntia Maria Basso}

\section{CONSIDERAÇÕES INICIAIS}

Ouvir e ler histórias é entrar em um mundo encantador, cheio ou não de mistérios e surpresas, mas sempre muito interessante, curioso, que diverte e ensina. É na relação lúdica e prazerosa da criança com a obra literária que temos uma das possibilidades de formarmos o leitor. É na exploração da fantasia e da imaginação que instiga-se a criatividade e se fortalece a interação entre texto e leitor. Quem de nós não lembra com saudades das histórias lidas e ouvidas quando crianças? Daquela historinha contada por nossos pais ao pé da cama antes de dormir? Ou daquela contada e interpretada pela professora nas primeiras séries do ensino fundamental?

$\mathrm{Na}$ interação da criança com a obra literária está a riqueza dos aspectos formativos nela apresentados de maneira fantástica, lúdica e simbólica. A intensificação dessa interação, através de procedimentos pedagógicos adequados, leva a criança a uma maior compreensão do texto e a uma compreensão mais abrangente do contexto. Uma obra literária é aquela que mostra a realidade de forma nova e criativa, deixando espaços para que o leitor descubra o que está nas entrelinhas do texto.

A literatura infantil, portanto, não pode ser utilizada apenas como um "pretexto" para o ensino da leitura e para o incentivo à formação do hábito de ler. Para que a obra literária seja utilizada como um objeto mediador de conhecimento, ela necessita estabelecer relações entre teoria e prática, possibilitando ao professor atingir determinadas finalidades educativas. Para tanto, uma metodologia baseada em um ensino por projetos é uma das possibilidades que tem evidenciado bons resultados no ensino de língua materna.

\section{UM POUCO DA HISTÓRIA DA LITERATURA INFANTIL}

A literatura infantil divide-se em dois momentos: a escrita e a lendária. A lendária nasceu da necessidade que tinham as mães de se comunicar com seus filhos, de contar coisas que os rodeavam, sendo estas apenas contadas, não sendo registradas por escrito. Os primeiros livros infantis surgiram no século XVII, quando da escrita das histórias contadas oralmente. Foram obras de fundo satírico, concebidas por intelectuais que lutavam contra a opressão para estigmatizar e condenar usos, costumes e personagens que oprimiam o povo. Os autores, para não serem atingidos pela força do despotismo, foram obrigados a esconder suas intenções sob um manto fantasioso (Cademartori, 1994).

O início da literatura infantil pode ser marcado com Perrault, entre os anos de 
1628 e 1703, com os livros "Mãe Gansa", "O Barba Azul", "Cinderela", "A Gata Borralheira", "O Gato de Botas" e outros. Depois disso, apareceram os seguintes escritores: Andersen, Collodi, Irmãos Grimm, Lewis Carrol, Bush. No Brasil, a literatura infantil pode ser marcada com o livro de Andersen "O Patinho Feio", no século XX. Após surgiu Monteiro Lobato, com seu primeiro livro "Narizinho Arrebitado" e, mais adiante, muitos outros que até hoje cativam milhares de crianças, despertando o gosto e o prazer de ler (Cademartori, 1994).

\section{LITERATURA INFANTIL: UM MUNDO DE IMAGINAÇÃO, SONHOS E FANTASIAS}

A criança que desde muito cedo entra em contato com a obra literária escrita para ela terá uma compreensão maior de si e do outro. Terá a oportunidade de desenvolver seu potencial criativo e ampliar os horizontes da cultura e do conhecimento, percebendo o mundo e a realidade que a cerca. Para Bettelheim (1996),

enquanto diverte a criança, o conto de fadas a esclarece sobre si mesma, e favorece o desenvolvimento de sua personalidade. Oferece significado em tantos níveis diferentes, e enriquece a existência da criança de tantos modos que nenhum livro pode fazer justiça à multidão e diversidade de contribuições que esses contos dão à vida da criança (p.20).

Na concepção de Aguiar \& Bordini (1993),

a obra literária pode ser entendida como uma tomada de consciência do mundo concreto que se caracteriza pelo sentido humano dado a esse mundo pelo autor. Assim, não é um mero reflexo na mente, que se traduz em palavras, mas o resultado de uma interação ao mesmo tempo receptiva e criadora. Essa interação se processa através da mediação da linguagem verbal, escrita ou falada ... (p.14).

Concordando com essas autoras, Cademartori (1994, p.23), afirma que

... a literatura infantil se configura não só como instrumento de formação conceitual, mas também de emancipação da manipulação da sociedade. Se a dependência infantil e a ausência de um padrão inato de comportamento são questões que se interpenetram, configurando a posição da criança na relação com o adulto, a literatura surge como um meio de superação da dependência e da carência por possibilitar a reformulação de conceitos e a autonomia do pensamento.

Poucas crianças têm o hábito de ler em nosso país. A maioria tem o primeiro contato com a literatura apenas quando chega à escola. E a partir daí, vira obrigação, pois infelizmente muitos de nossos professores não gostam de 
trabalhar com a literatura infantil e talvez desconheçam técnicas que ajudem a "dar vida às histórias" e que, conseqüentemente, produzam conhecimentos. Muitos não levam em conta o gosto e a faixa etária em que a criança se encontra, sendo que muitas vezes o livro indicado ou lido pelo professor está além das possibilidades de compreensão dela em termos de linguagem.

Uma história traz consigo inúmeras possibilidades de aprendizagem. Entre elas estão os valores apontados no texto, os quais poderão ser objeto de diálogo com as crianças, possibilitando a troca de opiniões e o desenvolvimento de sua capacidade de expressão. O estabelecimento de relações entre os comportamentos dos personagens da história e os comportamentos das próprias crianças em nossa sociedade possibilita ao professor desenvolver os múltiplos aspectos educativos da literatura infantil.

Experiências felizes com a literatura infantil em sala de aula são aquelas em que a criança interage com os diversos textos trabalhados de tal forma que possibilite $o$ entendimento do mundo em que vivem e que construam, aos poucos, seu próprio conhecimento. Para alcançarmos um ensino de qualidade, se faz necessário que o professor descubra critérios e que saiba selecionar as obras literárias a serem trabalhadas com as crianças. Ele precisa desenvolver recursos pedagógicos capazes de intensificar a relação da criança com o livro e com seus próprios colegas. Segundo Bettelheim (1996),

para que uma estória realmente prenda a atenção da criança, deve entretê-la e despertar sua curiosidade. Mas para enriquecer sua vida, deve estimular-lhe a imaginação: ajudá-la a desenvolver seu intelecto e a tornar claras suas emoções; estar harmonizada com suas ansiedades e aspirações; reconhecer plenamente suas dificuldades e, ao mesmo tempo, sugerir soluções para os problemas que a perturbam ... (p.13).

Ao trazer a literatura infantil para a sala de aula, o professor estabelece uma relação dialógica com o aluno, o livro, sua cultura e a própria realidade. Além de contar ou ler a história, ele cria condições em que a criança trabalhe com a história a partir de seu ponto de vista, trocando opiniões sobre ela, assumindo posições frente aos fatos narrados, defendendo atitudes e personagens, criando novas situações através das quais as próprias crianças vão construindo uma nova história. Uma história que retratará alguma vivência da criança, ou seja, sua própria história. De acordo com Abramovich (1995, p.17),

ler histórias para crianças, sempre, sempre ... É poder sorrir, rir, gargalhar com as situações vividas pelas personagens, com a idéia do conto ou com o jeito de escrever dum autor e, então, poder ser um pouco cúmplice desse momento de humor, de brincadeira, de divertimento ... É também suscitar o imaginário, é ter a curiosidade respondida em relação a tantas perguntas, é encontrar outras idéias para solucionar questões (como as personagens fizeram ....). É uma possibilidade de descobrir o mundo imenso dos conflitos, 
dos impasses, das soluções que todos vivemos e atravessamos - dum jeito ou de outro - através dos problemas que vão sendo defrontados, enfrentados (ou não), resolvidos (ou não) pelas personagens de cada história (cada uma a seu modo) ... É a cada vez ir se identificando com outra personagem (cada qual no momento que corresponde àquele que está sendo vivido pela criança) ... e, assim, esclarecer melhor as próprias dificuldades ou encontrar um caminho para a resolução delas ...

Portanto, a conquista do pequeno leitor se dá através da relação prazerosa com o livro infantil, onde sonho, fantasia e imaginação se misturam numa realidade única, e o levam a vivenciar as emoções em parceria com os personagens da história, introduzindo assim situações da realidade.

é ouvindo histórias que se pode sentir (também) emoções importantes, como a tristeza, a raiva, a irritação, o bemestar, o medo, a alegria, o pavor, a insegurança, a tranqüilidade, e tantas outras mais, e viver profundamente tudo o que as narrativas provocam em quem as ouve - com toda a amplitude, significância e verdade que cada uma delas fez (ou não) brotar ... Pois é ouvir, sentir e enxergar com os olhos do imaginário! (Abramovich, 1995, p. 17).

\section{UM ENSINO POR PROJETOS}

A Pedagogia de Projetos é um tipo especial de pesquisa-ação que também está preocupada com a melhora e transformação da prática social, sendo centrada em uma sucessão organizada de tarefas. Segundo Richter 1997, a Pedagogia de Projetos

... consiste em uma Investigação-Ação cuja ação social transformadora a realizar é (essencialmente) uma ação comunicativa. Esta pode se corporificar em diferentes linguagens e veículos; mas pretende operar alguma modificação no ambiente social abrangido pelo veículo da comunicação ... é um ensino-baseado-em-tarefa ... é um ensino centrado no aluno, processual em termos de todos os parâmetros de curso ... a aquisição da linguagem se dá em bases interacionistas ... (p. 55, "não paginado").

Os Parâmetros Curriculares Nacionais (PCNs) da Língua Portuguesa também mencionam o ensino por meio de projetos. Segundo os autores,

os projetos são excelentes situações para que os alunos produzam textos de forma contextualizada - além do que, dependendo de como se organizam, exigem leitura, escuta de leituras, produção de textos orais, estudo, pesquisa e outras atividades. ... Os projetos, além de oferecerem reais condições de produção de textos escritos, carregam 
exigências de grande valor pedagógico:

- podem apontar a necessidade de ler e analisar uma grande variedade de textos e portadores do tipo que se vai produzir: como se organizam, que características possuem ou quais têm mais qualidade ...;

- o exercício de o escritor ajustar o texto à imagem que faz do leitor fisicamente ausente permite que o aluno aprenda a produzir textos escritos mais completos, com características de textos escritos mesmo ...;

- ... a necessidade de revisão e de cuidado com o trabalho se impõe, pois a legibilidade passa a ser um objetivo deles ...;

- ... é possível uma intersecção entre conteúdos de diferentes áreas ...;

- ... favorecem o necessário compromisso do aluno com sua própria aprendizagem ... (1997, p.70-73).

O trabalho com a literatura infantil desenvolvido via projetos proporciona uma "vida cooperativa" no ambiente de sala de aula. A criança passa a viver com mais responsabilidades e autonomia, fazendo parte de um grupo que incentiva e provoca conflitos. Um ensino por projetos, portanto,

é permitir a crianças que construam o sentido de sua atividade de aluno. É aceitar que um grupo viva com suas alegrias, entusiasmos, conflitos, choques, com sua experiência própria e todos os lentos caminhos que levam às realizações complexas. Vida cooperativa da aula e projetos ... Projetos referentes à vida cotidiana, projetosempreendimentos, projetos de aprendizado, cooperativamente definidos, cooperativamente construídos, cooperativamente avaliados ... (Jolibert, 1994a, p.21).

Através da Pedagogia de Projetos, a criança antecipa e organiza o texto adequadamente, exigindo de sim mesma que leve a sua tarefa até o fim. Entretanto, por mais autônoma que seja, a criança não deixa de aceitar a ajuda que seus parceiros podem oferecer-Ihe e vice-versa, adquirindo, desta forma, auto-estima e senso crítico. No ensino por projetos, a criança não age passivamente, ela

... conhece seus objetivos; aprende a planejar seu trabalho, que irá se estender por várias sessões; irá produzir um tipo de texto identificado desde o começo; engaja-se pessoalmente na escrita; tem necessidade de uma turma para confrontar e melhorar sua produção ..." (Jolibert, 1999b, p.34).

Em um ensino por projetos destaca-se a produção coletiva e colaborativa do conhecimento, implicando em: a) organização, por parte do grupo, do que se quer 
escrever; b) o controle entre o que já está escrito e o que falta escrever; c) o acordo entre as crianças que fazem parte do grupo; d) a distribuição de tarefas e responsabilidades.

Portanto, em um ensino através de projetos, segundo Jolibert (1994a),

A vida cooperativa da sala de aula, e da escola, e a prioridade conferida à prática da elaboração e conduta de projetos explicitadamente definidos juntos permitem, de uma maneira exemplar, que a criança viva seus processos autônomos de aprendizado e se insira num grupo e num meio considerados como estrutura que estimula, que exige, que valoriza, que provoca contradições e conflitos e que cria responsabilidades. Fazer viver uma aula cooperativa é efetuar uma escolha de educador. Significa acabar com o monopólio do adulto que decide, recorta, define ele mesmo as tarefas e torna asséptico o meio. É fazer a escolha de um processo que leva a turma a se organizar, a dar-se as regras de vida e de funcionamento, gerir seu espaço, seu tempo e seu orçamento. Para conseguir tal empreendimento tem de: escolher, engajar-se, implementar, responsabilizarse, regular, realizar, discutir, comentar, criticar, avaliar, viver (p.20-21).

\section{CONSIDERAÇÕES FINAIS}

Acredito que a educação seja um espaço para descobertas obtidas através da participação e colaboração ativa de cada criança com seus parceiros em todos os momentos, possibilitando, assim, a construção de sujeitos autônomos e cooperativos.

É, portanto, através de um ensino por projetos, que a literatura infantil ganhará um sentido maior na vida das crianças. O confronto de opiniões, a motivação, as interações sociais e o trabalho cooperativo possibilitarão à criança condições que asseguram o caráter formativo das atividades, através de uma boa orientação do professor, tendo a finalidade de esclarecer aos alunos o que devem fazer, como devem fazer, por que e para que fazer tal atividade ou ler este ou aquele livro. $\mathrm{Na}$ literatura infantil, portanto, a criança aprende brincando em um mundo de imaginação, sonhos e fantasias.

\section{BIBLIOGRAFIA}

ABRAMOVICH, F. Literatura infantil: gostosuras e bobices. 5.ed. São Paulo : Scipione, 1995.

AGUIAR, V.T. \& BORDINI, M.G. Literatura: a formação do leitor: alternativas metodológicas. 2.ed. Porto Alegre : Mercado Aberto, 1993.

BETTELHEIM, B. A psicanálise dos contos de fadas. 11.ed. Rio de Janeiro : 
Paz e Terra, 1996. p. 11-43.

BRASIL. Ministério da Educação. Secretaria de Educação Fundamental. Parâmetros Curriculares Nacionais: Língua Portuguesa. Brasília : MEC/SEF, 1997.

CADEMARTORI, L. O que é literatura infantil? 6.ed. São Paulo : Brasiliense, 1994.

JOLIBERT, J. Formando crianças leitoras. Porto Alegre : Artes Médicas, 1994. v.1 1994. V.2

Formando crianças produtoras de textos. Porto Alegre : Artes Médicas,

RICHTER, M.G.. Pedagogia de projeto no ensino do português. Santa Maria : UFSM , 1997. "Não paginado. Digitado". 